\title{
IS ULNAR NERVE ENTRAPMENT AT WRIST FREQUENT AMONG PATIENTS WITH CARPAL TUNNEL SYNDROME OCCUPATIONALLY EXPOSED TO MONOTYPE WRIST MOVEMENTS?
}

\section{MAGDALENA LEWAŃSKA and JOLANTA WALUSIAK-SKORUPA}

Nofer Institute of Occupational Medicine, Łódź, Poland

Department of Occupational Diseases and Environmental Health, Out-patient Clinic of Occupational Diseases

\begin{abstract}
Objectives: Association between carpal tunnel syndrome (CTS) and ulnar nerve entrapment at wrist remains controversial. The aim of the study has been to investigate the prevalence of Guyon's canal syndrome amongst patients diagnosed with the CTS, occupationally exposed to repetitive wrist movements. Material and Methods: The retrospective analysis of 310 patients (268 females, 42 males) representing the mean age of $52 \pm 7$ years old hospitalized for the suspected occupational CTS was performed. Results: In the analyzed cohort, 4 patients had undergone decompression of the Guyon's canal in the right limbs. Nerve conduction studies (NCS) in the ulnar nerves performed during the hospitalization of those patients did not show any abnormalities. Nerve conduction studies revealed signs of the ulnar neuropathy (UN) at the wrist affecting exclusively sensory fibers for 6 patients. Only those 4 patients who had undergone the operation suffered from clinical symptoms of the UN before the surgery. In the case of the remaining patients, despite the NCS changes, signs suggestive of the UN at the wrist were not detected. In the case of the patients with the occupational CTS, no signs of the ulnar nerve dysfunction were recorded. Conclusions: The frequency of ulnar nerve entrapment at the wrist among patients with the CTS is lower than that already reported. The low prevalence of ulnar involvement (3.2\%) for the CTS patients in our study may be related to the relatively small number of the CTS hands with the severe changes in the NCS and/or other personal factor including anatomical variation of the Guyon's canal borders and its contents. Int J Occup Med Environ Health 2017;30(6):861-874
\end{abstract}

Key words:

Carpal tunnel syndrome, Guyon's canal syndrome, Nerve conduction studies, Ulnar neuropathy, Occupational monotype wrist movements, Occupational CTS

\section{INTRODUCTION}

Carpal tunnel syndrome (CTS) is the most frequent entrapment neuropathy observed in clinical practice. Compression of the median nerve may result from narrowing of the canal or crowding of the median nerve by the other elements within the carpal tunnel. Many systemic disorders and personal factors increase the risk of the development of the CTS [1-5]. It is also the most common

Funding: the study was conducted in 2015 and 2016 as part of the Nofer Institute of Occupational Medicine project IMP 12.22 entitled "Prevalence of ulnar nerve entrapment at the wrist among patients with carpal tunnel syndrome occupationally exposed to monotype wrist movements" financed with the resources granted by the Ministry of Science and Higher Education. Project manager: Magdalena Lewańska, M.D., Ph.D.

Received: March 16, 2016. Accepted: August 22, 2016.

Corresponding author: M. Lewańska, Nofer Institute of Occupational Medicine, Department of Occupational Diseases and Environmental Health, Out-patient Clinic of Occupational Diseases, św. Teresy 8, 91-348 Łódź, Poland (e-mail: mlewanska@interia.pl). 
leading cause of work-related upper extremity musculoskeletal disorders due to repetitive and forceful exertions of the hand and use of vibrating hand tools $[6,7]$.

Patients complain of nocturnal numbness, pain, tingling and painful paresthesia in the area supplied by the median nerve fibers (mostly on the I, II, III fingers and the radial half of the IV finger), sometimes with additional radiation of the aliments to the forearm, arm and even shoulder, followed by a reduction of the grip strength and impaired function of the affected hand. Patients suffering from the CTS often report sensory symptoms extending to the whole hand [8], even more frequently in both the median and ulnar digits than in the median digits alone [9].

It suggests ulnar nerve entrapment at wrist in the ulnar canal (the Guyon's canal) since the canal is in close contiguity with carpal tunnel. Shea and McClain [10] have classified lesions of the ulnar nerve in Guyon's canal into 3 types, depending on the anatomical site at the wrist at which the ulnar nerve is compromised. For the type I, the lesion is proximal to or within Guyon's canal and involves both the superficial and deep branches, and causes a mixed motor and sensory deficit, with weakness involving all the ulnar hand muscles and affecting sensation of the medial 1.5 digits. For the type II, the location of lesion is within Guyon's canal or at the piso-hamate hiatus, along the deep branch and there is only weakness in muscles innervated by the deep branch. Depending on the location, it may spare hypothenar muscles. Types I and II are always associated with atrophy of the first dorsal interosseous muscle. For the type III, the location of lesion in the end of the Guyon's canal causes only sensory abnormalities on palmar ulnar distribution. There is no motor deficit. For the type I and III lesions, sensory loss does not occur on the dorsum of the hand, innervated by the dorsal ulnar cutaneous sensory branch, and should largely spare the hypothenar eminence because its innervation is via the palmar cutaneous branch, which arises proximal to the wrist.
Wu et al. [11] proposed ulnar neuropathy (UN) at wrist divided into 5 types, based on clinical findings, electrophysiological studies and/or clinical and anatomical correlations. For the type I, lesion occurs either outside or within the proximal end of Guyon's canal and causes the mixed motor and sensory neuropathy involving all the ulnar hand muscles and affecting sensation of the medial 1.5 digits. For the type II there is purely sensory neuropathy, where the lesion involves the superficial branch of ulnar nerve at the wrist but distal to the branch to the palmaris brevis muscle. The type III lesion occurs in the deep motor branch distal to the superficial branch but proximal to the branch to the hypothenars. This compression site results in a purely motor neuropathy affecting all intrinsic muscles of the hand, including the hypothenar muscles. The type IV is a pure motor ulnar neuropathy with sparing of hypothenars; this lesion occurring on the deep branch of the ulnar nerve distal to the origin of the superficial branch and distal to the branch extending to the hypothenars. The type $\mathrm{V}$ lesion occurs just proximal to the branches supplying the first dorsal interosseous (FDI) and adductor pollicis muscles, resulting in weakness of these muscles groups only.

The carpal and ulnar (Guyon's) tunnels lie adjacent to each other. The volar carpal ligament forms the roof of carpal tunnel and the floor of the ulnar canal. The chance that high pressure in the carpal tunnel in the CTS reflects on the adjacent ulnar canal, causing indirect compression of ulnar nerve is considered [12-15].

However, the relationship of the CTS with entrapment of the ulnar nerve at the Guyon's canal is still disputable. The occupational overuse may cause not only the CTS but also the ulnar neuropathy at the Guyon's canal $[16,17]$. Therefore, the aim of the study has been to evaluate with the use of standard nerve conduction examinations - the prevalence of entrapment of the ulnar nerve at the wrist in patients with established diagnosis of the CTS, occupationally exposed to repetitive wrist movements. 


\section{MATERIAL AND METHODS}

The study was scheduled as the retrospective analysis of 334 patients (290 females, 44 males), aged $52 \pm 7$ years old, who were admitted to the Department of Occupational Diseases and Environmental Health of the Nofer Institute of Occupational Medicine (NIOM), Łódź, Poland, from November 2010 till June 2013 for the suspected occupational CTS. The participants were residents of various, either urban or rural areas. All the patients were evaluated using the same clinical and neurophysiological protocol.

The clinical diagnosis of the CTS was defined as the presence of at least 1 of the following symptoms [18]: paresthesia, swelling, weakness or clumsiness of the hand provoked or aggravated by sleep, sustained hand or arm position, repetitive movements of the hand or wrist, sensory deficit in median nerve distribution, isolated weakness and/or atrophy of the median innervated thenar muscle, positive Tinel's or Phalen's signs.

The clinical history and clinical examination were obtained by a neurologist and occupational medicine physician. Neurophysiological evaluation and laboratory tests were carried out to detect other diseases that could be related to the CTS. Detailed analysis of workplace exposure was performed to determine possible occupational etiology of the neuropathy. Careful medical history, clinical examination, evaluation of previous magnetic resonance imaging (MRI) and computed tomography (CT) scans and results of nerve conduction studies were used for excluding the patients with polyneuropathy, cervical radiculopathy, myelopathy and ulnar neuropathy at the elbow.

As the occupational overuse attributed to repetitive prolonged flexion or extension of the wrist [16] and working with vibratory equipment [17] may cause not only the CTS but also the ulnar neuropathy at the Guyon's canal, patients with diagnosed occupational origin of the CTS were included in the final analysis.

The clinical diagnosis of the CTS was confirmed by nerve conduction studies (NCS) performed according to the American Association of Electrodiagnostic Medicine (AAEM) guidelines $[19,20]$ by a certified clinical neurophysiologist and neurophysiology technician, using Medtronic Keypoint R Net electromyography (EMG) apparatus (Alpine Biomed A/S, Denmark). The values of distal latencies, conduction velocities and amplitudes were determined for motor and sensory branches of both median and ulnar nerves in all of the cases. All latencies were measured to the onset of the compound muscle action potential (CMAP) and the initial negative peak of the sensory action potential (SNAP). Normal values of the NCS standard parameters for age were based on a previous local population study of healthy subjects consisting of some of the NIOM staff and volunteers (enlisted earlier for clinical practice and research studies [21]). Abnormal values were defined as $>2$ standard deviations of normal mean values. Surface electrodes were used for all neurographic tests and the extremities were warmed up if the skin temperature was $<32^{\circ} \mathrm{C}$, which is routine practice in our EMG laboratory. The temperature of the skin was measured using a Micro life NC 100 thermometer (Microlife AG, Switzerland).

Neurophysiological tests included: sensory orthodromic conduction in the median and ulnar nerves, with stimulation using ring electrodes at the index and the fifth digit and registration of SNAPs for median and ulnar nerves at the wrist $14 \mathrm{~cm}$ and $13 \mathrm{~cm}$, respectively; motor conduction of the median nerve registered at the abductor pollicis brevis (APB) muscle with stimulation at the wrist $(8 \mathrm{~cm}$ to recording electrode); motor conduction of the ulnar nerve registered at the abductor digiti minimi (ADM) muscle with stimulation at the wrist ( $8 \mathrm{~cm}$ to recording electrode). Elbow-wrist motor NCS were performed to exclude median or ulnar nerve involvement proximal to the wrist and the presence of anomalous median-ulnar communication in the forearm [22]. The ulnar nerve was extensively studied, particularly at the segment across the elbow, to determine the presence of focal damage to the nerve at 
the elbow according to the AAEM (American Association of Electrodiagnostic Medicine), AAN (American Academy of Neurology), AAPMR (American Academy of Physical Medicine and Rehabilitation) practice parameter guideline [23].

If standard tests: sensory nerve conduction velocity (CV) in 2 digit-wrist segments and median distal motor latency (DML) from wrist to APB muscle had yielded normal results, comparative tests were always done. Evaluation of the difference between median and ulnar sensory latencies using a fixed $14 \mathrm{~cm}$ length over wrist to IV finger (Digit 4 Median-Digit 4 Ulnar - D4M-D4U) distance and/or assessment of the difference between distal median motor latency recording from the second lumbrical muscle (2L) and distal ulnar motor latency, recording from the underlying second interossei muscle (2I) (Second Lumbrical and Interossei Distal Motor Latency Difference - 2LI-DML) with a fixed distance $(10 \mathrm{~cm})$ between the stimulating (at wrist) and the receiving electrode were performed.

If there had been a conduction abnormality in the sensory fibers of ulnar nerve, sensory antidromic conduction of the median and radial nerves would have been registered at the thumb, with stimulation $10 \mathrm{~cm}$ (to active electrode) at the nerve trajectory, at the wrist (Digit 1 Median-Digit 1 Radial - D1M-D1R) [24].

The electrophysiological diagnostic criteria of the CTS included the following: prolonged median motor latency ( $\geq 4.2 \mathrm{~ms}$ ) and/or prolonged median sensory peak latency $\geq 3.6 \mathrm{~ms}$ at the wrist combined with the difference of $>0.6 \mathrm{~ms}$ between the DML from the median and ulnar nerves to the second lumbrical and interosseous muscle, respectively (2LI-DML > $0.6 \mathrm{~ms}$ ) [25] and/or the median-radial sensory peak latency difference (Digit 1 Median-Digit 1 Radial Sensory Latency Difference - D1MD1R SLD) of $>0.4 \mathrm{~ms}$ [24] and/or the median-ulnar sensory peak latency difference (Digit 4 Median-Digit 4 Ulnar Sensory Latency Difference - D4M-D4U, SLD) of $>0.4 \mathrm{~ms}[24,26]$.
A SNAP peak latency $>3.5 \mathrm{~ms}$ and/or DML $>3.3 \mathrm{~ms}$ were the electrodiagnostic criteria for ulnar involvement. As a routine practice in our EMG laboratory, if there had been any suspicion of distal ulnar neuropathy, assessment of absolute distal motor latency (DML) to the first dorsal interosseous (FDI) muscle as well as differences between the DML to FDI and the ADM on the same side (normal value $\leq 2 \mathrm{~ms}$ ) and differences in the side-to-side (normal value $\leq 1.3 \mathrm{~ms}$ ) [27] and bilateral sensory nerve conduction examination of the dorsal ulnar cutaneous nerve (according to the procedure described by Kim et al. [28]) was done. In the case of any medical indication, NCS of lower extremities (bilateral peroneal, tibial nerves motor conduction, and sural nerves sensory conduction studies) were performed to exclude polyneuropathies.

In the study, only patients with an exclusive clinical and confirmed neurophysiological diagnosis of the CTS were analyzed. The severity of the electrophysiological CTS was categorized following the AAEM electrodiagnostic guidelines, developed by Padua et al. [29,30]: the extreme CTS (absence of thenar motor or sensory responses), the severe CTS (absence of sensory response and abnormal DML), the moderate CTS (abnormal digit-wrist sensory conduction and abnormal DML), the mild CTS (abnormal digit - wrist sensory conduction and normal DML), the minimal CTS (exclusive abnormal segmental and/or comparative study), and the negative CTS (normal findings in all tests).

\section{RESULTS}

The process used for identifying cases of the CTS meeting the goal of the study is described in the Figure 1. Twenty-three patients with coexisting neuropathy of the ulnar nerve at the elbow level and 1 patient with polyneuropathy out of the 334 CTS cases were not included in the final analysis. In the group of 310 examined patients (268 women, $42 \mathrm{men}$ ), 257 had bilateral and 53 unilateral CTS (44 right CTS - R-CTS, 9 left CTS - L-CTS). 


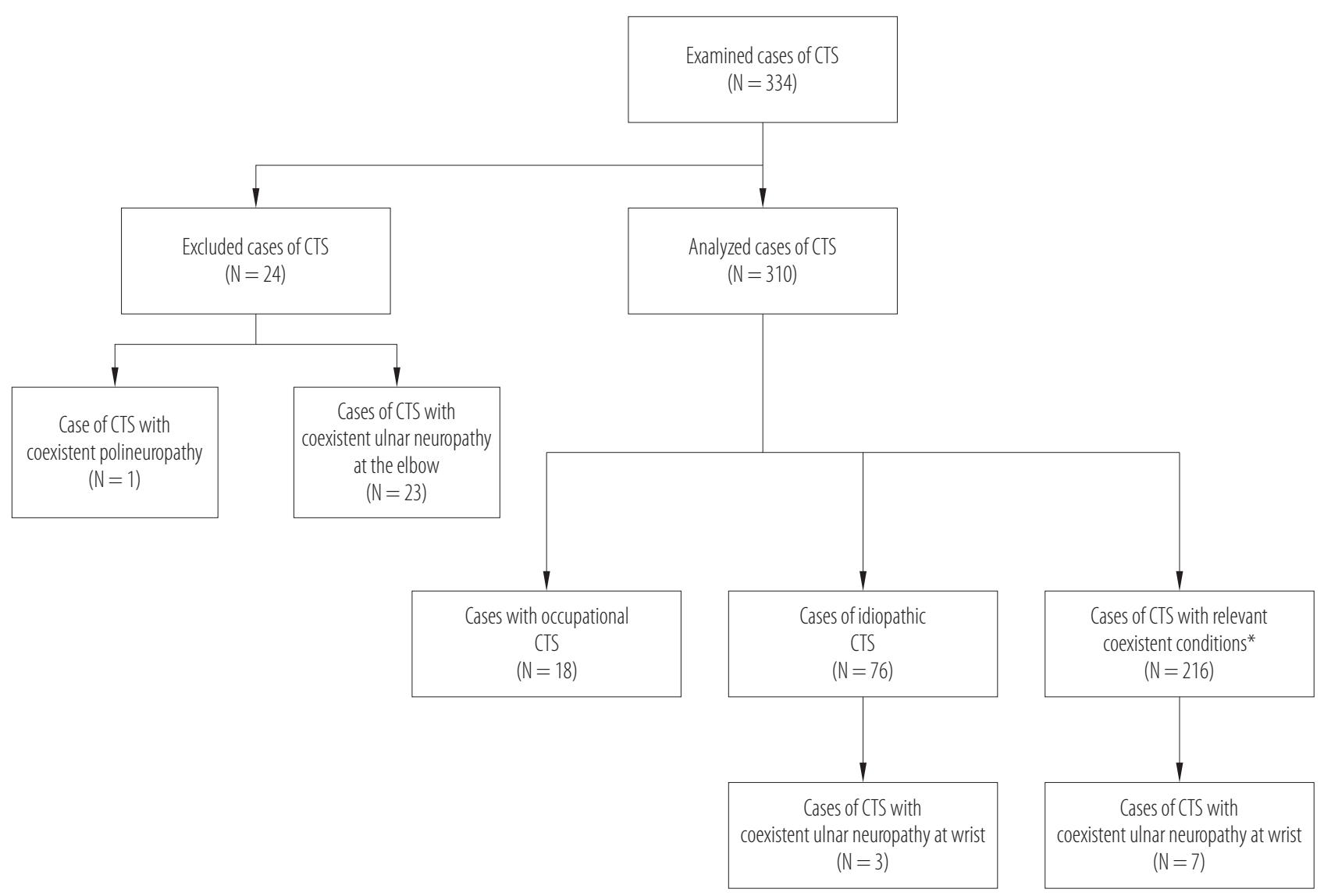

* Table 3 shows details concerning percentage of cases with coexistent conditions thought to be associated with increased risk of CTS.

Fig. 1. Patients hospitalized for suspected occupational carpal tunnel syndrome (CTS)

In total, 620 wrists (86 right and 35 left after carpal tunnel release, 300 after bilateral surgery, 146 wrists with the CTS receiving only conservative treatment, and 53 wrist with no clinical signs of any neuropathy) were evaluated. The average age of the study population was $52 \pm 7$ years old. Full characteristics of the study population is shown in the Table 1.

The most numerous category among the respondents included the administrative staff $(\mathrm{N}=113)$ and the persons employed in manufacturing $(\mathrm{N}=109)$, mainly industrial workers and craftsmen. The Table 2 shows employment structure of the study population.

Two hundred sixteen patients were affected by diseases and systemic factors that may potentially predispose to the CTS. The Table 3 presents frequency of diseases significant for the pathogenesis of the CTS amongst patients from our study group.

Although the nature of the jobs performed by the entire population of the patients was repetitive, the detailed analysis of occupational exposures and the clinical analysis excluded the impact of the occupational exposure on development of median neuropathy at wrist for 76 patients who were diagnosed with the idiopathic CTS. Only 18 patients, including 15 women and 3 men were diagnosed with work-related carpal tunnel syndrome. The characteristics of the patients with the occupational carpal tunnel syndrome are presented in the Table 4.

Four patients in the analyzed cohort (310 patients) had undergone decompression of the Guyon's canal in the 
Table 1. Characteristics of the study group - patients hospitalized for suspected occupational carpal tunnel syndrome (CTS)

\begin{tabular}{lr}
\hline \multicolumn{1}{c}{ Characteristics } & $\begin{array}{r}\text { Respondents } \\
(\mathrm{N}=310)\end{array}$ \\
\hline $\begin{array}{l}\text { Sex }[\mathrm{n}(\%)] \\
\text { women }\end{array}$ & $268(86.45)$ \\
men & $42(13.54)$ \\
Age [years] $(\mathrm{M} \pm \mathrm{SD})$ & \\
$\quad$ total & $52.0 \pm 7.00$ \\
women & $52.0 \pm 6.80$ \\
men & $52.0 \pm 8.30$ \\
Duration of the occupational & \\
$\quad$ exposure to repetitive movements & \\
in the wrist [years] $(\mathrm{M} \pm \mathrm{SD})$ & \\
total & $19.8 \pm 9.69$ \\
women & $19.0 \pm 9.40$ \\
men & $24.3 \pm 10.30$ \\
\hline
\end{tabular}

right limbs. Unfortunately, despite the final conclusion of neurographic tests performed among those patients before surgery, raw NCS data was not accessible. The neurographic tests performed during the hospitalization did not show abnormalities of the neuromuscular conduction in the ulnar nerves, neither at the operated limb nor at the opposite side. Nerve conduction studies revealed signs of the ulnar nerve neuropathy at the wrist affecting exclusively sensory fibers for 6 patients: for 1 patient in the right upper extremity, for 4 patients - in the left upper limb, for 1 patient - bilateral. Two patients had demyelinating, 3 - an axonal and 1 - mixed (axonal/demyelinating) changes in the ulnar sensory fibers.

The analysis of the clinical data showed that only 4 patients who had undergone the ulnar nerve release in the Guyon's canal showed clinical symptoms of the ulnar neuropathy before the surgery. In the case of the remaining patients, despite the changes recorded

M - mean; SD - standard deviation.

Table 2. Professions in study group according to Statistical Classification of Economic Activities in the European Community (NACE)

\begin{tabular}{|c|c|c|c|}
\hline \multirow{2}{*}{ NACE section } & \multicolumn{3}{|c|}{$\begin{array}{c}\text { Respondents } \\
{[\mathrm{n}(\%)]}\end{array}$} \\
\hline & $\begin{array}{c}\text { total } \\
(\mathrm{N}=310)\end{array}$ & $\begin{array}{c}\text { women } \\
(\mathrm{N}=268)\end{array}$ & $\begin{array}{c}\text { men } \\
(\mathrm{N}=42)\end{array}$ \\
\hline Agriculture, hunting, forestry and fishing & $13(4.2)$ & $11(3.5)$ & $2(0.6)$ \\
\hline Mining and quarrying & $1(0.3)$ & $1(0.3)$ & $0(0)$ \\
\hline Manufacturing & $109(35.2)$ & $81(26.1)$ & $28(9.0)$ \\
\hline Electricity, gas, steam and air conditioning supply & $1(0.3)$ & $0(0)$ & $1(0.3)$ \\
\hline Water supply; sewerage, waste management and remediation activities & $0(0)$ & $0(0)$ & $0(0)$ \\
\hline Construction & $2(0.6)$ & $1(0.3)$ & $1(0.3)$ \\
\hline Trade; repair of motor vehicles & $8(2.6)$ & $7(2.3)$ & $1(0.3)$ \\
\hline Transportation and storage & $3(1.0)$ & $1(0.3)$ & $2(0.6)$ \\
\hline Accommodation and catering & $9(2.9)$ & $9(2.9)$ & $0(0)$ \\
\hline Information and communication & $3(1.0)$ & $2(0.6)$ & $1(0.3)$ \\
\hline Financial and insurance activities & $1(0.3)$ & $1(0.3)$ & $0(0)$ \\
\hline Real estate activities & $0(0)$ & $0(0)$ & $0(0)$ \\
\hline
\end{tabular}


Table 2. Professions in study group according to Statistical Classification of Economic Activities in the European Community (NACE) - cont.

\begin{tabular}{|c|c|c|c|}
\hline \multirow{2}{*}{ NACE section } & \multicolumn{3}{|c|}{$\begin{array}{l}\text { Respondents } \\
{[\mathrm{n}(\%)]}\end{array}$} \\
\hline & $\begin{array}{c}\text { total } \\
(\mathrm{N}=310)\end{array}$ & $\begin{array}{c}\text { women } \\
(\mathrm{N}=268)\end{array}$ & $\begin{array}{c}\text { men } \\
(\mathrm{N}=42) \\
\end{array}$ \\
\hline Professional, scientific and technical activities & $3(1.0)$ & $3(1.0)$ & $0(0)$ \\
\hline Administrative and support service activities & $113(36.5)$ & $110(35.5)$ & $3(1.0)$ \\
\hline Public administration and defence; compulsory social security & $0(0)$ & $0(0)$ & $0(0)$ \\
\hline Education & $2(0.6)$ & $2(0.6)$ & $0(0)$ \\
\hline Human health and social work activities & $28(9.0)$ & $26(8.4)$ & $2(0.6)$ \\
\hline Arts, entertainment and recreation & $2(0.6)$ & $2(0.6)$ & $0(0)$ \\
\hline Other service activities & $12(3.9)$ & $11(3.5)$ & $1(0.3)$ \\
\hline
\end{tabular}

Table 3. Patients with coexistent conditions potentially associated with an increased risk of carpal tunnel syndrome (CTS)

\begin{tabular}{lc}
\hline Non-occupational etiologic factors of CTS & $\begin{array}{c}\text { Respondents } \\
(\mathrm{N}=216) \\
{[\mathrm{n}(\%)]}\end{array}$ \\
\hline Obesity & $104(48.1)$ \\
Thyroid diseases, endocrinopathy & $82(37.96)$ \\
Hormonal therapy and/or oophorectomy & $49(22.68)$ \\
Rheumatoid arthritis, systemic diseases & $19(8.79)$ \\
Diabetes & $36(16.66)$ \\
Hand/wrist trauma/local changes in carpal & $11(5.09)$ \\
$\quad$ tunnel/carpometacarpal (CMC) arthritis & \\
Gout & $5(2.31)$ \\
Nonspecific tendovaginitis & $9(4.16)$ \\
Multiple associated conditions & $113(52.31)$ \\
\hline
\end{tabular}

in the neurographic examination, signs suggestive of the ulnar neuropathy at the wrist were detected neither during history taking nor clinical testing. Amongst the patients with the occupational CTS, neither clinical nor neurographical signs of the ulnar nerve dysfunction were recorded. The Table 5 shows the characteristics of patients with the CTS and concomitant ulnar neuropathy at the wrist and a history of pre-hospital surgical
Table 4. Characteristics of patients with diagnosed occupational carpal tunnel syndrome (CTS)

\begin{tabular}{|c|c|}
\hline Characteristics & $\begin{array}{c}\text { Respondents } \\
\quad(\mathrm{N}=18)\end{array}$ \\
\hline \multicolumn{2}{|l|}{$\operatorname{Sex}[\mathrm{n}(\%)]$} \\
\hline women & $15(83.3)$ \\
\hline men & $3(16.7)$ \\
\hline \multicolumn{2}{|l|}{ Age [years] $(\mathrm{M} \pm \mathrm{SD})$} \\
\hline total & $42.0 \pm 7.0$ \\
\hline women & $47.0 \pm 7.0$ \\
\hline men & $43.0 \pm 5.9$ \\
\hline \multicolumn{2}{|c|}{$\begin{array}{l}\text { Time of the occupational exposure } \\
\text { to repetitive movements } \\
\text { in the wrist [years] }(\mathrm{M} \pm \mathrm{SD})\end{array}$} \\
\hline total & $20.2 \pm 9.3$ \\
\hline women & $20.4 \pm 10.8$ \\
\hline men & $19.0 \pm 8.9$ \\
\hline
\end{tabular}

Abbreviations as in Table 1.

decompression of Guyon's canal. The analysis of electrophysiological abnormalities in the analyzed cohort according to the classification of CTS severity as reported by Padua et al. [29,30] revealed a higher number of moderate and mild than the severe CTSs (Table 6). 
Table 5. Patients with carpal tunnel syndrome (CTS) and coexisting ulnar neuropathy at the wrist (UNW)

\begin{tabular}{|c|c|c|c|c|}
\hline \multirow{2}{*}{$\begin{array}{l}\text { Respondents } \\
\text { (sex, age) }\end{array}$} & \multirow{2}{*}{$\begin{array}{l}\text { Clinical } \\
\text { symptoms } \\
\text { of the UNW }\end{array}$} & \multicolumn{2}{|l|}{ CTS } & \multirow{2}{*}{$\begin{array}{c}\text { UNW } \\
\text { BIL/R/L location } \\
\text { ulnar NCS changes }\end{array}$} \\
\hline & & $\begin{array}{c}\mathrm{BIL} / \mathrm{R} / \mathrm{L} \text { location } \\
\text { surgical treatment / median NCS changes }\end{array}$ & $\begin{array}{l}\text { possible etiologic } \\
\text { factors }\end{array}$ & \\
\hline \multicolumn{5}{|l|}{ Woman } \\
\hline 55 years old & $\begin{array}{l}\text { yes (before } \\
\text { the Guyon's } \\
\text { canal release) }\end{array}$ & $\begin{array}{l}\text { BIL CTS } \\
\text { underwent BIL carpal tunnel release } \\
\text { BIL median normal NCS }\end{array}$ & idiopathic CTS & $\begin{array}{l}\text { underwent R Guyon's } \\
\text { canal release } \\
\text { normal ulnar NCS }\end{array}$ \\
\hline 37 years old & $\begin{array}{l}\text { yes (before } \\
\text { the Guyon's } \\
\text { canal release) }\end{array}$ & $\begin{array}{l}\text { R CTS } \\
\text { underwent R carpal tunnel release } \\
\text { BIL median normal NCS }\end{array}$ & $\mathrm{BMI}=30$ & $\begin{array}{l}\text { underwent R Guyon's } \\
\text { canal release } \\
\text { normal ulnar NCS }\end{array}$ \\
\hline 51 years old & $\begin{array}{l}\text { yes (before } \\
\text { the Guyon's } \\
\text { canal release) }\end{array}$ & $\begin{array}{l}\text { BIL CTS } \\
\text { underwent R carpal tunnel release } \\
\mathrm{R} \text { median NCS } \uparrow 2 \mathrm{LI} \text {-DML, } \uparrow \text { DSL } \\
\mathrm{L} \text { median NCS } \uparrow \mathrm{DSL}\end{array}$ & $\mathrm{BMI}=30.7$ & $\begin{array}{l}\text { underwent R Guyon's } \\
\text { canal release } \\
\text { normal ulnar NCS }\end{array}$ \\
\hline 52 years old & $\begin{array}{l}\text { yes (before } \\
\text { the Guyon's } \\
\text { canal release) }\end{array}$ & $\begin{array}{l}\text { R CTS } \\
\text { underwent R carpal tunnel release } \\
\text { BIL median NCS normal }\end{array}$ & $\mathrm{BMI}=31.9$ & $\begin{array}{l}\text { underwent R Guyon's } \\
\text { canal release } \\
\text { normal ulnar NCS }\end{array}$ \\
\hline 49 years old & no & $\begin{array}{l}\text { L CTS } \\
\text { underwent L carpal tunnel release } \\
\text { BIL median normal NCS }\end{array}$ & $\begin{array}{l}\text { nonspecific } \\
\text { tendovaginitis } \\
\text { diabetes }\end{array}$ & $\begin{array}{l}\text { UNW L } \\
\text { NCS: } \downarrow \text { SNAP }\end{array}$ \\
\hline 57 years old & no & $\begin{array}{l}\text { BIL CTS } \\
\text { underwent BIL carpal tunnel release } \\
\text { R median NCS normal } \\
\text { L median NCS: } \uparrow \text { DSL }\end{array}$ & $\begin{array}{l}\text { hypothyroidism } \\
\text { diabetes } \\
\text { oophorectomy }\end{array}$ & $\begin{array}{l}\text { UNW R } \\
\text { NCS: } \downarrow \text { SNAP }\end{array}$ \\
\hline 44 years old & no & $\begin{array}{l}\text { BIL CTS } \\
\text { underwent R carpal tunnel release } \\
\text { R median NCS normal } \\
\text { L median NCS: } \uparrow \text { DML, } \uparrow \text { DSL }\end{array}$ & $\begin{array}{l}\mathrm{BMI}=36.5 \\
\text { hypothyroidism }\end{array}$ & $\begin{array}{l}\text { UNW L } \\
\text { NCS: } \uparrow \text { DSL }\end{array}$ \\
\hline 57 years old & no & $\begin{array}{l}\text { R CTS } \\
\text { underwent R carpal tunnel release } \\
\text { L median NCS normal } \\
\text { R median NCS: } \uparrow \text { DSL }\end{array}$ & idiopathic CTS & $\begin{array}{l}\text { BIL UNW } \\
\text { NCS: } \uparrow \text { DSL }\end{array}$ \\
\hline \multicolumn{5}{|l|}{ Man } \\
\hline 46 years old & no & $\begin{array}{l}\text { BIL CTS } \\
\text { underwent L carpal tunnel release } \\
\text { L median NCS: } \uparrow \text { DSL, } \downarrow \text { SNAP, } \uparrow \text { DML, } \downarrow \text { CMAP } \\
\text { R median NCS: } \uparrow \text { DSL, } \downarrow \text { SNAP, } \uparrow \text { DML, } \downarrow \text { CMAP }\end{array}$ & $\mathrm{BMI}=38.7$ & $\begin{array}{l}\text { UNW L NCS: } \\
\uparrow \text { DSL } \downarrow \text { SNAP }\end{array}$ \\
\hline 52 years old & no & $\begin{array}{l}\text { BIL CTS } \\
\text { underwent BIL carpal tunnel release } \\
\text { BIL median NCS normal }\end{array}$ & idiopathic CTS & UNW L $\downarrow$ SNAP \\
\hline
\end{tabular}

BIL - bilateral; R - right; L - left.

NCS - nerve conduction study; BMI - body mass index $\left(\mathrm{kg} / \mathrm{m}^{2}\right)$; 2LI-DML - second lumbrical and interossei distal motor latency difference; DSL - distal sensory latency; SNAP - sensory nerve action potential amplitude; DML - distal motor latency; CMAP - compound muscle action potential amplitude.

$\uparrow$ - increase; $\downarrow$ - decrease. 
Table 6. Electrophysiological abnormalities in the study group (patients hospitalized for suspected CTS), according to the electrophysiological classification of CTS severity

\begin{tabular}{lcc}
\hline & \multicolumn{2}{c}{$\begin{array}{c}\text { Study group } \\
\text { Severity of CTS in NCS* }\end{array}$} \\
\cline { 2 - 3 } & \multicolumn{2}{c}{ total wrists } \\
Extreme (EXT) & $(\mathrm{N}=620$ wrists $)$ & $\begin{array}{c}\text { non-operated wrists } \\
\text { (N = 146 wrists })\end{array}$ \\
Severe (SEV) & $0(0)$ & $0(0)$ \\
Moderate (MOD) & $10(1.6)$ & $6(4.1)$ \\
Mild (MIL) & $213(34.4)$ & $93(63.7)$ \\
Minimal (MIN) & $143(23.1)$ & $34(23.3)$ \\
Negative (NEG) & $70(11.3)$ & $13(8.9)$ \\
\hline
\end{tabular}

CTS - carpal tunnel syndrome; NCS - nerve conduction studies.

* Electrophysiological classification of CTS severity as reported by Padua et al.: Neurophysiological classification and sensitivity in 500 carpal tunnel syndrome hands [29], and Padua et al.: Neurophysiological classification of carpal tunnel syndrome: Assessment of 600 symptomatic hands [30]. Extreme (EXT) - absence of thenar motor or sensory responses; severe (SEV) - absence of sensory response and abnormal distal motor latency (DML); moderate (MOD) - abnormal digit-wrist conduction and abnormal DML; mild (MIL) - abnormal digit wrist conduction and normal DML; minimal (MIN) - exclusive abnormal segmental and/or comparative study; negative (NEG) - normal findings in all tests.

\section{DISCUSSION}

The prevalence of ulnar involvement for the CTS patients in our study was found to be low, about $3 \%$ (10 patients). Neurographical signs of the ulnar nerve neuropathy at the wrist concerning exclusively sensory fibers were recognized among 6 patients. Four patients had undergone decompression of the right Guyon's canal and had normal results in ulnar nerve conduction testing. To our knowledge, this is the first study on the frequency of ulnar nerve neuropathy at the wrist among the Polish CTS patients occupationally exposed to repetitive wrist movements. No reports have addressed specifically the incidence and prevalence of ulnar neuropathy at wrist in a general population. However, the first reports about the coexistence of neuropathy of the ulnar nerve in the Guyon's canal with the CTS date back to the early 70s of 20th century. Sedal et al. [14] in a retrospective analysis of 234 patients with the idiopathic CTS demonstrated coincidence of electrophysiological changes indicative of neuropathy of the ulnar nerve at the wrist for $44 \%$ of the patients (39.3\% of them had decreased ulnar SNAP amplitude and 4.8\% - had delayed ulnar SNAP distal latency). In a group of 248 patients with the CTS Cassvan et al. [15] found delayed ulnar SNAP peak latency at the wrist for $46 \%$ patients (bilateral in 100 and unilateral in 14 of the patients). Gozke et al. [31] recorded prolongation of ulnar nerve distal sensory latencies in 12 (18.4\%) out of 65 wrists of patients with the CTS.

In another report, 20 of 59 hands (34\%) of patients with the CTS had abnormalities in sensibility testing of both the median and ulnar nerves by either two-point discrimination, Semmes-Weinstein monofilament testing, or both. Fifty-three percent of patients complained of paresthesia and/or numbness in ulnar nerve distribution, while $41 \%$ had abnormal electromyographic testing of the ulnar nerve [12].

In contrast to the above data, other reports deny the existence of a causal link between the CTS and ulnar nerve entrapment at wrist. Murata et al. [32] conducted a retrospective study of 31 patients with Guyon's canal syndrome, clinically diagnosed and confirmed by electrophysiological examination. In the case of 17 patients, factors contributing 
to the pathogenesis of the neuropathy included traumatic factors, vascular abnormalities, anomalies of bone and soft tissue as well as tumors, while the remaining 14 patients were diagnosed with idiopathic ulnar tunnel syndrome. Although 12 out of 14 cases (86\%) of idiopathic ulnar tunnel syndrome at wrist were associated with the CTS, additionally 3 cases were associated also with diabetes mellitus.

Those authors stated that their analysis did not confirm a clinically relevant and significant relationship between ulnar neuropathy at wrist and the CTS. In a cross-sectional prospective study [33], the ulnar nerve involvement in the wrist of studied CTS patients was $4.2 \%$ (7 out of 165 evaluated hands).

Moghtaderi and Ghafarpoor [34] in a prospective case control study of 181 patients with the established idiopathic CTS found delayed distal latency ( $\geq 2.8 \mathrm{~ms}$ registered at $13 \mathrm{~cm}$ from stimulation site) for ulnar sensory branches in $7.5 \%$ patients, delayed distal latency ( $\geq 3.4 \mathrm{~ms}$ registered at $5 \mathrm{~cm}$ from stimulation site) for ulnar nerve motor branches in $4.6 \%$ patients and delayed peak latency ( $\geq 3.3 \mathrm{~ms}$ ) for ulnar sensory branches in $15 \%$ patients. The authors did not find statistically significant correlation between subgroups of the CTS patients and control group.

Our results do not support the earliest reports, however, they are similar to those reported by Vahdatpour et al. [33] and related findings. In the analyzed cohort, the ulnar involvement at the wrist was detected only for 3.2\% (10 cases) of patients with the CTS. Only 4 patients who - in addition to decompression of the carpal tunnel also underwent decompression of the Guyon's canal - reported clinical symptoms of the ulnar nerve neuropathy before the surgery. Unfortunately, the lack of the precise pre-surgery NCS data prevented comparison with other findings in our study. In the remaining 6 cases, the NCS showed signs of the ulnar entrapment at wrist, whereas neither clinical interview nor neurological examination revealed symptoms suggestive of the ulnar neuropathy.
It is worth noting that, in our research, clinical and electrophysiological signs of ulnar nerve dysfunction were not observed in patients with the CTS of occupational origin. Recognition of occupational etiology for these patients was based on documented long-term exposure to the repetitive movements of the wrist(s) often accompanied by prolonged strong grip and high pressure of hands on tools, as well as exposure to prolonged awkward posture of the hands. In one case, the subject was also exposed to mechanical vibrations. No changes in the ulnar nerve(s) at the wrist in these cases may be explained by that the work-related hand movements did not cause repetitive traumatic squeeze of the nerve inside Guyon's canal or repetitive traumatic pressure, particularly on the hypothenar portion of the palm. These could also depend on the individual's work technique [16,35]. In our research, 3 other patients were affected by diseases known to contribute to the development of neuropathy (diabetes [36,37], hypothyroidism [38,39]), which may explain the observed changes in the ulnar NCS. Although one of them had newly diagnosed hypothyroidism, the potential functional and structural changes in peripheral nerves and initially predominating demyelinating sensory symptoms might exist [40,41]. Despite the abnormalities in median and ulnar nerves, the NCS tests in nerves of lower limbs did not reveal signs of polyneuropathy. The reduction of amplitude of the SNAP of ulnar nerves in one patient was likely due to high body mass index (BMI) value (38.7) [42]. Ulnar nerve involvement at wrist was noted only in 3 cases of idiopathic CTS; out of those, one patient underwent surgical decompression of the right Guyon's canal, while neurographic tests carried out at the Department of Occupational Diseases and Environmental Health of NIOM, Łódź, Poland, showed no abnormalities in the ulnar nerve conduction. In the second case of the idiopathic CTS, NCS showed delayed bilateral ulnar SNAP latency.

The polyneuropathy was ruled out by the nerve conduction study in the left median peroneal and sural nerves of both limbs. Despite earlier surgical decompression of right 
carpal tunnel, the NCS disclosed the prolongation of right median sensory latency in that patient. The third one, who had undergone bilateral carpal tunnel release earlier with positive clinical effect (and withdrawal of bilateral median NCS changes) had decreased the left ulnar SNAP.

Although the typical sign of nerve entrapment is the demyelinisation causing the prolongation of distal latency and the slowing of the conduction velocity, the reduced or even absent ulnar SNAP of the little and ring fingers were described earlier for patients with ulnar neuropathy at wrist [43]. These NCS changes suggest involvement of the superficial branch of the ulnar nerve. Other authors reported decreased the ulnar SNAP amplitude recordings (from digit 4 and 5) in the moderate and severe grades of the CTS according electrophysiological severity scale [44]. Ginanneschi et al. [45] showed that the ulnar SNAP amplitudes were significantly lower for the CTS patients than in controls and the ulnar motor distal latency did not significantly differ from the control group. It is suggested that the ulnar abnormalities are attributable to functional (axon membrane potential and ion channel changes) rather than morphological (focal nerve demyelination) factors [46]. Rapidly reversed ulnar nerve clinical and neurographical symptoms following surgical carpal tunnel release for the CTS patients [12,47,48] supports the above theory, however, the decreased SNAP in this case seems to be of unclear origin. It is likely that ulnar nerve conduction might have been affected by various personal factors: lifestyle, everyday activities or local anatomical variations in Guyon's canal [49,50], including deformity or bulging of the canal by increased amount of fat tissue. Unfortunately, the retrospective nature of this study precludes definitive diagnosis of the etiology of these changes.

Considering spontaneous relief of ulnar nerve symptoms for the CTS patients following surgical release of carpal tunnel $[12,47,48]$, it is quite likely that the small percentage of electrophysiological abnormalities detected in the ulnar nerves at the wrist level in the study cohort was due to the relatively large group of patients who had undergone CTS surgery. However, only one case out of 146 wrists of the conservatively treated CTS patients presented electroneurographical signs of the ulnar neuropathy at the wrist.

According to previous reports [31,46] indicating that pathological process involving the ulnar nerve is associated with increasing severity of CTS, the results of our observation may be related to the relatively small number of CTS hands with the severe changes according to Padua scale $[29,30]$.

Ulnar nerve conduction testing is a standard procedure in the differential diagnosis of the CTS, while the detailed procedure is of particular importance, considering the CTS symptomatology, where the location of the sensory disturbances often extends beyond the typical median nerve area. The detection of neurographic abnormalities in the ulnar nerve at the wrist influences the choice of the alternative comparative NCS tests recommended in electrophysiological diagnosis of the CTS.

Despite the drawbacks difficult to avoid in a retrospective study, our study shows that special attention is required in the diagnostic procedure of the CTS, especially if other diseases are involved, that may cause neuropathy also in other peripheral nerves, including ulnar nerve in the Guyon's canal. Despite the divergent previous reports, documented volumetric and pressure increase in Guyon's canal among the CTS patients suggest that it is not reasonable to exclude the coincidence of neuropathy of the ulnar nerve at the wrist and the CTS. Perhaps gender, age or race affect the size and morphology of Guyon's canal may contribute to increased pressure in the carpal tunnel. However, it is still not clear whether the increase is attributable primarily to the anthropometric and/or demographic factors or to the severity and extent of medical conditions. This issue requires further prospective and multicenter studies in groups of patients with varied degree of severity of the neurographical idiopathic CTS changes, using 
the uniform NCS protocol taking into account the effects of age and other anthropometric factors on the assessed parameters, including Guyon's canal imaging.

\section{CONCLUSIONS}

The low prevalence of ulnar involvement (3.2\%) for the CTS patients in our study may be related to the relatively small number of the CTS hands with the severe changes in the NCS and/or other personal factors, such as anatomical variation of the Guyon's canal borders and its contents.

\section{REFERENCES}

1. Stevens JC, Beard CM, O'Fallon WM, Kurland LT. Conditions associated with carpal tunnel syndrome. Mayo Clin. Proc. 1992;67:541-8, https://doi.org/10.1016/S0025-6196(12)60461-3.

2. Nathan PA, Keniston RC. Carpal tunnel syndrome and its relation to general physical condition. Hand Clin. 1993;9: 253-61.

3. Nathan PA, Keniston RC, Meadows KD, Lockwood RS. The relationship between body mass index and the diagnosis of carpal tunnel syndrome. Muscle Nerve. 1994;17:1491-3.

4. Kouyoumdjian JA, Zanetta DM, Morita MP. Evaluation of age, body mass index, and wrist index as risk factors for carpal tunnel syndrome severity. Muscle Nerve. 2002;25:93-7, https://doi.org/10.1002/mus.10007.

5. Nathan PA, Meadows KD, Istvan JA. Predictors of carpal tunnel syndrome: An 11-year study of industrial workers. J Hand Surg Am. 2002;27:644-51, https://doi.org/10.1053/ jhsu.2002.34003.

6. Bernard BP, editor. Musculoskeletal disorders and workplace factors: A critical review of epidemiologic evidence for work-related musculoskeletal disorders of the neck, upper extremity and low back. Chapter 5. Hand/wrist musculoskeletal disorders (carpal tunnel syndrome, hand/wrist tendinitis, and hand-arm vibration syndrome): Evidence for work-relatedness. Cincinnati, US Department of Health and Human Services, 1997.
7. Van Rijn RM, Huisstede BM, Koes BW, Burdorf A. Associations between work-related factors and the carpal tunnel syndrome - A systematic review. Scand J Work Environ Health. 2009;35(1):19-36, https://doi.org/10.5271/sjweh.1306.

8. Nora DB, Becker J, Ehlers JA, Gomes I. Clinical features of 1039 patients with neurophysiological diagnosis of carpal tunnel syndrome. Clin Neurol Neurosurg. 2004;107(1):64-9, https://doi.org/10.1016/j.clineuro.2004.08.003.

9. Stevens JC, Smith BE, Weaver AL, Bosch EP, Deen HG, Wilkens JA. Symptoms of 100 patients with electromyographically verified carpal tunnel syndrome. Muscle Nerve. 1999;22(10):1448-56, https://doi.org/10.1002/(SICI)1097-45 98(199910)22:10<1448::AID-MUS17>3.0.CO;2-Y.

10. Shea JD, McClain EJ. Ulnar-nerve compression syndromes at and below the wrist. J Bone Joint Surg. 1969;51:1095-103.

11. Wu JS, Morris JD, Hogan GR. Ulnar neuropathy at the wrist: Case report and review of literature. Arch Phys Med Rehabil. 1985 Nov;66(11):785-8.

12. Silver MA, Gelberman RH, Gellman H, Rhoades CE. Carpal tunnel syndrome: Associated abnormalities in ulnar nerve function and effect of carpal tunnel release on these abnormalities. J Hand Surg. 1985;10A:710-3, https://doi. org/10.1016/S0363-5023(85)80214-8.

13. Gelberman R, Hergenroeder PT, Hargens AR, Lundborg GL, Akeson WK. The carpal tunnel syndrome. A study of carpal canal pressure. J Bone Joint Surg. 1981;71A: 679-83.

14. Sedal L, McLeod JG, Walsh JC. Ulnar nerve lesions associated with carpal tunnel syndrome. J Neurol Neurosurg Psychiatry. 1973;36:118-23, https://doi.org/10.1136/jnnp.36.1.118.

15. Cassvan A, Rosenberg A, Rivera LF. Ulnar nerve involvement in carpal tunnel syndrome. Arch Phys Med Rehabil. 1986;67:290-2.

16. Yassi A. Repetitive strain injuries. Lancet. 1997;3(9056): 943-7, https://doi.org/10.1016/S0140-6736(96)07221-2.

17. Rosén I, Strömberg T, Lundborg G. Neurophysiological investigation of hands damaged by vibration: Comparison with idiopathic carpal tunnel syndrome. Scand J Plast 
Reconstr Surg Hand Surg. 1993;27:209-16, https://doi.org/ 10.3109/02844319309078113.

18. Practice parameter for carpal tunnel syndrome (Summary statement). Neurology. 1993;43:2404-9, https://doi.org/10. 1212/WNL.43.11.2406.

19. Jablecki CK, Andary MT, Floeter MK, Miller RG, Quartly CA, Vennix MJ, et al. Practice parameter: Electrodiagnostic studies in carpal tunnel syndrome. Report of the American Association of Electrodiagnostic Medicine, American Academy of Neurology, and the American Academy of Physical Medicine and Rehabilitation. Neurology. 2002;58(11):158992, https://doi.org/10.1212/WNL.58.11.1589.

20. Practice parameter: Electrodiagnostic studies in ulnar neuropathy at the elbow. Summary statement of the American Association of Electrodiagnostic Medicine, American Academy of Neurology, and American Academy of Physical Medicine and Rehabilitation. Neurology. 1999;52(4):688-90, https://doi.org/10.1212/WNL.52.4.688.

21. Lewańska M, Wagrowska-Koski E, Walusiak-Skorupa J. [Etiological factors for developing carpal tunnel syndrome in people who work with computers]. Med Pr. 2013;64(1): 37-45, https://doi.org/10.13075/mp.5893/2013/0005. Polish.

22. Kimura J. Electrodiagnosis in diseases of nerve and muscle. Facts, fallancies, and fancies of nerve stimulation techniques. Anomalies as sources of errors. Martin-Gruber anastomosis. 3rd ed. New York: Oxford University Press; 2001. p. 187-90.

23. Practice parameter for electrodiagnostic studies in ulnar neuropathy at the elbow: Summary statement. Muscle Nerve. 1999;22(3):408-11, https://doi.org/10.1002/(SICI)1097-4598 (199903)22:3<408::AID-MUS16>3.0.CO;2-7.

24. Jackson DA, Clifford JC. Electrodiagnosis of mild carpal tunnel syndrome. Arch Phys Med Rehabil. 1989;70:199-204.

25. Al-Shekhlee A, Fernandes Filho JA, Sukul D, Preston DC. Optimal recording electrode placement in the lumbricalinterossei comparison study. Muscle Nerve. 2006;33(2): 289-93, https://doi.org/10.1002/mus.20488.

26. Johnson EW, Kukla RD, Wongsam PE, Piedmont A. Sensory latencies to the ring finger: Normal values and relation to carpal tunnel syndrome. Arch Phys Med Rehab. 1981;62:206-8.

27. Olney RK, Wilbourn AJ. Ulnar nerve conduction study of the first dorsal interosseus muscle. Arch Phys Rehabil. 1985;66:16-8.

28. Kim DJ, Kalantri A, Guha S, Wainapel SF. Dorsal cutaneus nerve conduction: Diagnostic aid in ulnar neuropathy. Arch Neurol. 1981;38:321-2, https://doi.org/10.1001/archneur.1981.00510050087021.

29. Padua L, LoMonaco M, Gregori B. Neurophysiological classification and sensitivity in 500 carpal tunnel syndrome hands. Acta Neurol Scand. 1997;96(4):211-7, https://doi. org/10.1111/j.1600-0404.1997.tb00271.x.

30. Padua L, LoMonaco M, Padua R. Neurophysiological classification of carpal tunnel syndrome: Assessment of 600 symptomatic hands. Ital J Neurol Sci. 1997;18(3):145-50, https:// doi.org/10.1007/BF02048482.

31. Gozke E, Dortcan N, Kocer A, Cetinkaya M, Akyuz G, Us O. Ulnar nerve entrapment at wrist associated with carpal tunnel syndrome. Neurophysiol Clin. 2003;33:219-22, https://doi.org/10.1016/j.neucli.2003.08.002.

32. Murata K, Shih JT, Tsai TM. Causes of ulnar tunnel syndrome: A retrospective study of 31 subjects. J Hand Surg Am. 2003;28:647-51, https://doi.org/10.1016/S0363-5023(03) 00147-3.

33. Vahdatpour B, Raissi GR, Hollisaz MT. Study of the ulnar nerve compromise at the wrist of patients with carpal tunnel syndrome. Electromyogr Clin Neurophysiol. 2000;47:183-6.

34. Moghtaderi A, Ghafarpoor M. The dilemma of ulnar nerve entrapment at wrist in carpal tunnel syndrome. Clin Neurol Neurosurg. 2009;111(2):151-5, https://doi.org/10.1016/ j.clineuro.2008.09.012

35. Shapiro BE, Preston DC. Entrapment and compressive neuropathies. Med Clin North Am. 2009;93(2):285-315, https:// doi.org/10.1016/j.mena.2008.09.009.

36. Hyllienmark L, Alstrand N, Jonsson B, Ludvigsson J, Cooray G, Wahlberg Topp J. Early electrophysiological abnormalities and clinical neuropathy. A prospective study in pa- 
tients with type 1 diabetes. Diabetes Care. 2013;36:3187-94, https://doi.org/10.2337/dc12-2226.

37. Pirart J. Diabetes mellitus and its degenerative complications. A prospective study of 4,400 patients observed between 1947 and 1973. Diabetes Care. 1978;1(3):168-88, https://doi.org/10.2337/diacare.1.3.168.

38. Duyff RF, van den Bosch J, Laman DM, Potter van Loon BJ, Linssen JP. Neuromuscular findings in thyroid dysfunction: A prospective clinical and electrodiagnostic study. J Neurol Neurosurg Psychiatry. 2000;68:750-5, https://doi. org/10.1136/jnnp.68.6.750.

39. Mahadule AA, Jadhao PS, Phatak MS. Motor conduction parameters in recently diagnosed and untreated hypothyroidism. Ann Neurosci. 2015;22(1):6-10, https://doi.org/ 10.5214/ans.0972.7531.220103.

40. Asia AA, Warkar AB. Nerve conduction studies in recently diagnosed untreated hypothyroid patients. Indian J Basic Appl Med Res. 2015;4(4):330-4.

41. Arikanoglu A, Altun Y, Uzar E, Acar A, Cevik MU, Demircan F. Electrophysiological examination of the median and ulnar nerve in patients with clinical and subclinical hypothyroidism: A case-control study. Arch Neuropsychiatry. 2012;49(4):304-7, https://doi.org/10.4274/npa.y6258.

42. Buschbacher RM. Body mass index effect on common nerve conduction study measurements. Muscle Nerve. 1998;21:1398-404， https://doi.org/10.1002/(SICI)1097-4598 (199811)21:11<1398::AID-MUS6>3.0.CO;2-4.

43. Kimura J. Electrodiagnosis in diseases of nerve and muscle. Principles and practice. Part VIII. Disorders of the spinal cord and peripheral nervous system. 3rd ed. New York: Oxford University Press; 2001. p. 727.
44. Saba EKA, El-Tawab SS. Ulnar nerve changes associated with carpal tunnel syndrome not affecting median versus ulnar comparative studies. World J Med Sci. 2014;11(4):600-8, https://doi.org/10.5829/idosi.wjms.2014.11.4.91113.

45. Ginanneschi F, Milani P, Mondelli M, Dominici F, Biasella A, Rossi A. Ulnar sensory nerve impairment at the wrist in carpal tunnel syndrome. Muscle Nerve. 2008;37:183-9, https://doi.org/10.1002/mus.20905.

46. Ginanneschi F, Dominici F, Milani P, Biasella A, Rossi A. Evidence of altered motor axon properties of the ulnar nerve in carpal tunnel syndrome. Clin Neurophysiol. 2007;118: 1569-76, https://doi.org/10.1016/j.clinph.2007.03.024.

47. Ablove RH, Moy OJ, Peimer CA, Wheeler DR, Diao E. Pressure changes in Guyon's canal after carpal tunnel release. J Hand Surg Br. 1996;21:664-5, https://doi.org/10.10 16/S0266-7681(96)80155-0.

48. Ginanneschi F, Milani P, Rossi A. Anomalies of ulnar nerve conduction in different carpal tunnel syndrome stages. Muscle Nerve. 2008;37:1155-60, https://doi.org/10.1002/ mus.21070.

49. Zeiss J, Jakab E, Khimji T, Imbriglia J. The ulnar tunnel at the wrist (Guyon's canal): Normal MR anatomy and variants. AJR Am J Roentgenol. 1992 May;158(5):1081-5, https://doi.org/10.2214/ajr.158.5.1566671.

50. Jerome CP, Moncayo V, Terk MR. The Guyon's canal in perspective: 3-T MRI assessment of the normal anatomy, the anatomical variations and the Guyon's canal syndrome. Surg Radiol Anat. 2011;33(10):897-903, https://doi.org/10.1007/ s00276-011-0842-6.

This work is available in Open Access model and licensed under a Creative Commons Attribution-NonCommercial 3.0 Poland License - http://creativecommons.org/ licenses/by-nc/3.0/pl/deed.en. 